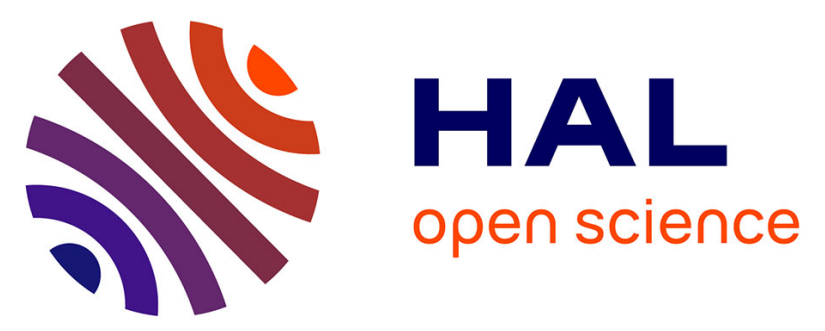

\title{
Self-awareness assessment during cognitive rehabilitation in children with acquired brain injury: a feasibility study and proposed model of child anosognosia
} Agata Krasny-Pacini, Jennifer Limond, Jonathan Evans, Jean Hiebel, Karim Bendjelida, Mathilde Chevignard

\section{To cite this version:}

Agata Krasny-Pacini, Jennifer Limond, Jonathan Evans, Jean Hiebel, Karim Bendjelida, et al.. Selfawareness assessment during cognitive rehabilitation in children with acquired brain injury: a feasibility study and proposed model of child anosognosia. Disability and Rehabilitation, 2015,37 (22), pp.2092 - 2106. 10.3109/09638288.2014.998783. hal-01513645

\section{HAL Id: hal-01513645 \\ https://hal.sorbonne-universite.fr/hal-01513645}

Submitted on 25 Apr 2017

HAL is a multi-disciplinary open access archive for the deposit and dissemination of scientific research documents, whether they are published or not. The documents may come from teaching and research institutions in France or abroad, or from public or private research centers.
L'archive ouverte pluridisciplinaire HAL, est destinée au dépôt et à la diffusion de documents scientifiques de niveau recherche, publiés ou non, émanant des établissements d'enseignement et de recherche français ou étrangers, des laboratoires publics ou privés. 


\section{$\underline{\text { Title }}$}

Self-Awareness assessment during cognitive rehabilitation in children with acquired brain injury: a feasibility study and proposed model of child anosognosia.

\section{Author names}

Krasny-Pacini Agata ${ }^{1,4}$, Limond Jennifer ${ }^{3}$, Evans Jonathan ${ }^{3}$, Hiebel Jean ${ }^{1}$, Bendjelida Karim ${ }^{5}$, Chevignard Mathilde ${ }^{2,4}$

Affiliations:

1. Institut Universitaire de Réadaptation Clemenceau-Strasbourg, 45 bd Clemenceau, 67082 Strasbourg, France Paediatric Department and Hautepierre Strasbourg University Hospital, Strasbourg. France

2. Rehabilitation Department for Children with Acquired Brain Injury, Hôpitaux de Saint Maurice, 14, rue du Val d’Osne, 94410 Saint Maurice

3. Mental Health and Wellbeing, Institute of Health \& Wellbeing, University of Glasgow, Gartnavel Royal Hospital, 1055 Great Western Rd, Glasgow G12 0XH , Scotland, UK

4. Sorbonne Universités, UPMC Univ Paris 06; CNRS,UMR 7371, LIB, F-75006 and UMR_S 1146, LIB, F75005, Paris, France

5. EMOI-TC 68, Hôpital du Hasenrain, 87 avenue d'Altkirch 68051 Mulhouse Cedex, France

Corresponding author:

Agata Krasny-Pacini

agatakrasny@yahoo.com; 0033671284152

agata.krasnygecam-alsace.fr; 0033388211647 or 42

Institut Universitaire de Réadaptation Clemenceau-Strasbourg, 45 bd Clemenceau, 67082 Strasbourg, France

\section{Declaration of interest}

The authors report no declarations of interest.

\section{Disclosure of funding received for this work}

This study was supported by scholarships, from the "SOFMER" (French Society of Physical and Rehabilitation Medicine), the "SFERHE" (French Research Society against Children's handicap) and the "Fondation Gueules Cassées". 


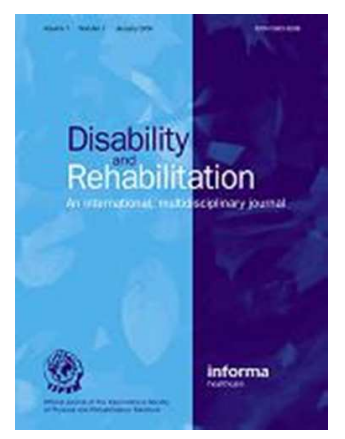

\section{SELF-AWARENESS ASSESSMENT DURING COGNITIVE REHABILITATION IN CHILDREN WITH ACQUIRED BRAIN INJURY: A FEASIBILITY STUDY AND PROPOSED MODEL OF CHILD ANOSOGNOSIA.}

\begin{tabular}{|r|l|}
\hline Journal: & Disability and Rehabilitation \\
\hline Manuscript ID: & TIDS-11-2014-053.R1 \\
\hline Manuscript Type: & Research Paper \\
\hline Keywords: & $\begin{array}{l}\text { self-awareness, cognitive rehabilitation, executive functions, children, brain } \\
\text { injury, model }\end{array}$ \\
\hline \multicolumn{2}{|l}{} \\
\hline
\end{tabular}

SCHOLARONE ${ }^{m}$

Manuscripts 
Implications for rehabilitation :

- Self-awareness has multiple components that need to be assessed separately, to better adapt cognitive rehabilitation

- Using questionnaires and discrepancy scores is not sufficient to assess awareness, because it does not include on-line error detection, which can be massively impaired in children, especially those with impaired executive functions.

- On-line error detection is important to promote and error-full learning is useful to allow a child to build a self-knowledge of his/her strengths and difficulties, in the absence of severe episodic memory problems.

- Metacognitive trainings may not be appropriate for younger children who have age appropriate developmentally immature self-awareness, nor for patients with brain injury if they suffer anosognosia because of their brain injury.

URL: http:/mc.manuscriptcentral.com/dandr Email: davemuller@suffolk.ac.uk 

PROPOSED MODEL OF CHILD ANOSOGNOSIA.

\section{ABSTRACT}

- Purpose: to compare three ways of assessing self-awareness in children with traumatic brain injury and to propose a model of child anosognosia

- Method: five single cases of children with severe traumatic brain injury, aged 8 to 14 , undergoing metacognitive training. Awareness was assessed using three different measures: two measures of metacognitive knowledge/intellectual awareness (a questionnaire and illustrated stories where child characters have everyday problems related to their executive dysfunction) and one measure of on-line/emergent awareness (post-task appraisal of task difficulty).

- Results: All three measures showed good feasibility. Analysis of awareness deficit scores indicated large variability (1\%-100\%). Three children showed dissociated scores.

- Conclusions: Based on these results, we propose a model of child self-awareness and anosognosia and a framework for awareness assessment for rehabilitation purposes. The model emphasizes (1) the role of on-line error detection in the construction of autobiographical memories that allow a child to build a self-knowledge of of his/her strengths and difficulties; (2) the multiple components of awareness that need to be assessed separately; (3) the implications for rehabilitation: errorless versus error-full learning, rehabilitation approaches based on metacognition, rationale for rehabilitation intervention based on child's age and impaired awareness component, ethical and developmental consideration of confrontational methods.

\section{INTRODUCTION}

Metacognition is the conscious knowledge of one's own cognitive processes as well as the processes involved in consciously monitoring and regulating one's ongoing actions [1]. Thus metacognition refers to the awareness of one's own cognition and is used in the context of normal functioning. The concept of awareness/self-awarness (or more usually lack of awareness), on the other hand, is usually used in the context of pathology and refers to the awareness of one's deficits, including cognitive deficits. As such, awareness can be viewed as metacognition applied to difficulties in cognitive functioning. 
Awareness and metacognition have been defined in many ways and there is little agreement among neuropsychologists, psychologists, developmentalists and education researchers as to the exact nature and limit of the two concepts. In developmental psychology, metacognition is thought to comprise metacognitive knowledge and metacognitive skills. Metacognitive knowledge is defined by Flavell as knowledge about one's own cognitive strengths and limitations, including factors that may interact to affect cognition [2]. The concept of metacognitive skills, refers to the voluntary control of cognitive processes including prediction, planning, monitoring and evaluation of behaviors.

Many models of awareness and metacognition have been proposed for adults [3]. Two models of awareness/metacognition are particularly useful: (1) Crosson's model [4] that offers a pragmatic classification of awareness levels linked with efficient compensation which can be proposed in each level and (2) Toglia and Kirk's comprehensive model of awareness after brain injury [5].

Crosson's model has an hierarchical structure, although this hierarchy has never been confirmed empirically[6]. At the base of awareness is intellectual awareness. Intellectual awareness comprises three sublevels: (a) the basic understanding that a deficit exists, (b) the recognition of a common thread in the activities the patient is impaired in, (c) the implications this has. On-line Awareness (also called emergent awareness) refers to the ability to recognize a problem while performing an activity. Emergent awareness is crucial to rehabilitation as patients who do not realize that a problem is occurring will not recognize the need to correct it and /or to initiate compensation. Anticipatory awareness is the highest level of awareness in Crosson's model, and is defined as the ability to anticipate that a problem will occur as a result of some deficit, and take some action to prevent that problem occurring.

Toglia and Kirk's comprehensive model of awareness after brain injury views the relationship between different aspects of metacognition and awareness as a dynamic process rather than as a series of hierarchical levels. It clearly differentiates between knowledge and beliefs related to one's self (i.e. metacognitive knowledge that preexists and is stored within long term memory) and 
knowledge and awareness that is activated during a task (i.e. on-line awareness which Toglia and Kirk define as "the ability to monitor performance "on-line", within the stream of action") [5].

Metacognitive knowledge is what one brings to a task, whereas on-line awareness involves ongoing evaluation of performance within the context of a task [7][5]. Metacognitive knowledge and on-line awareness are distinct functions and have been found not to be correlated in adults with brain injury [8].

Although Crosson's and Toglia and Kirk's models offer two distinct frameworks to study awareness, we argue they are complementary and that their combined use allows a better understanding of patients' difficulties: (1) Crosson's Intellectual awareness corresponds to the metacognitive knowledge of Toglia and Kirk's model; (2) Crosson's emergent awareness corresponds to on-line awareness of Toglia and Kirk's model (and comprises metacognitive "skills" from the field of developmental psychology); (3) anticipatory awareness is the behavioral manifestation of good metacognitive knowledge and good on-line awareness. Hereafter, the terms of awareness and metacognition will be used interchangeably, postulating that they have the same underlying construct, irrespective of its application to pathology or to normal functioning. Correspondence between the models and vocabulary used in developmental psychology are summarized in figure 1.

\section{Insert Fig 1 about here}

Impaired awareness/metacognition, sometimes also termed "anosognosia", is a common phenomenon described in children who have sustained a traumatic brain injury (TBI) [9][10][11]. However it results from a combination of organically based unawareness (due to brain injury) and simple developmental immaturity [11] present in typically developing children as well. Metacognition is known to be poorer in younger children. Even typically developing children are not "fully aware": they may have some basic intellectual awareness about things they cannot do that their parents can, however they are not able to fully understand the consequences of their cognitive limitations in recognizing a problem when it is actually happening, or predicting a problem will occur as a result of

3 Awareness pilot study, November 2014

URL: http:/mc.manuscriptcentral.com/dandr Email: davemuller@suffolk.ac.uk 
some developmental immaturity. Children only gradually come to gain awareness over the entire span of developmental years [11]. This has been mainly studied in relation to memory (termed metamemory) in typically developing children who show gradual development of metamemory throughout childhood [12]' [13]' [14]' [15]' [16] and in the field of learning disabilities [17]' [18]' [19][20]. Nelson and Narens proposed a comprehensive model of metacognition in metamemory [21] where metacognition is described as the interplay between two levels of information processing (an object-level processing and a meta-level processing) that interact with feedforward and feedback control and monitoring loops. A neural description of the model has been proposed by Shimamura[22].

To the best of our knowledge metacognition in relation to other cognitive functions, and especially executive function (EF)/complex task management in daily life, has not yet been explored. Here we will focus on metacognition for executive functions and complex task management in children with TBI because EF deficits are a frequent and disabling consequence of TBI [23] [24] and because TBI outcome is strongly predicted by executive functioning level[25].

Although metacognition is poor in young children, it has been shown to be even poorer in children who have sustained a brain injury [9][10][11][26][27][28]. However, to date, objective measurement of awareness in children with TBI is scarce (see Wales et al. [29] for a review) and most studies evaluate single metacognitive skills such as prediction, evaluation and confidence of performance[30] [31] [32] [33] [34]. Conversely, Beardmore et al. reported the use of the "Knowledge Interview for Children" (KIC) [9], a semi- structured interview related to twelve areas of knowledge about TBI (coma, story of the accident, brain functioning...) and ten potential areas of difficulty (attention, fatigue, memory, behavior...). Interview of the child and the parents yields an Awareness Discrepancy Index, by summing the number of items endorsed by the child's parents but rejected by the child. Children reported significantly less problems than their parents and demonstrated extremely limited knowledge about TBI. The SAND-C (Subjective Awareness of Neuropsychological Deficits

4 Awareness pilot study, November 2014

URL: http:/mc.manuscriptcentral.com/dandr Email: davemuller@suffolk.ac.uk 
Questionnaire for Children) is a self-report instrument in which children are required to estimate their neuropsychological functions [25], however self report is not compared to parental judgment and as such is not a measure of anonosgnosia if used alone.

Josman et al. evaluated children with TBI in relation to metamemory [31]and categorizations skills [35] with three types of self-awareness measures (1) intellectual awareness -termed general awareness by the authors (e.g.: "have you noticed any changes in memory?"), (2) self-prediction (of task difficulty[35]; "how many pictures will you remember ?" [31]) and (3) self-estimation of performance after the task. General awareness questions were not fully understood by the children and therefore not recommended. Prediction was difficult in both healthy children and children with TBI, self-estimation was significantly less correlated with actual performance in brain-injured children than in typically developing ones [35], and children with brain injury overestimated their memory performance [31]. Similarly, in Hanten et al. [32] [33] and Crowther et al. [34] studies, children who had sustained a TBI had poor estimation of their memory span and overconfidence in performance when compared to healthy children and children with mild TBI [32], suggesting impaired metacognition. The scarce literature assessing awareness in children with brain injury explores metacognitive skills such as prediction and evaluation, using assessments performed in structured, un-ecological environments. Questionnaires of intellectual awareness (KIC, SAND-C) proposed to date are not domain specific and do not specifically explore awareness of executive functioning.

The use of metacognitive training is a practice standard in adults with deficits in executive functioning [36]. Adult metacognitive training programmes, such as Goal Management Training (GMT) [37] have begun to be used in children[38]. GMT is mostly known for its algorithm "STOP ! Define the main task - List the steps -Learn the steps - Do it - Check" that can be used to train specific tasks [39]. However, the full GMT version [40] is a truly "metacognitive" training in that GMT encourages patients to think about their cognitive failures, to identify factors promoting or preventing these failures and to reflect and monitor how their thoughts may drift away from the

5 Awareness pilot study, November 2014

URL: http:/mc.manuscriptcentral.com/dandr Email: davemuller@suffolk.ac.uk 
main goal and switch to "automatic pilot". When used alone, GMT group training [41] [40] does not offer a repetitive intensive practice of EF and monitoring skills, but rather teaches and prompts the patients to monitor their actions, to detect their cognitive slips and gain control over their actions, through a conscious and attention-demanding monitoring of their flow of thoughts and actions. The relatively short duration of the programme $(7 \times 2$ hours of group training in adults, including GMT theory presentation and group discussions) does not allow automatisation of monitoring and checking. Rather, it relies on patient's awareness of difficulties and ability to actively implement the GMT algorithm in daily life, under conscious and 'top-down' control. Therefore GMT in adults relies heavily on a patient's awareness. A patient who considers that his/her cognition is efficient, will not easily engage in such an attention-demanding programme aiming at improving cognition efficiency in an effortful way. Awareness (before treatment or acquired throughout the GMT programme) is a core factor for programme success. GMT programmes usually enroll patients with mild or moderate brain injuries with relatively preserved awareness or integrate an awareness intervention component before the GMT [42][43].

As young children with brain injuries have impaired awareness because of developmental immaturity [11] added to the organically based awareness deficits due to their injury, metacognitive training programmes such as GMT may not be effective because the core factor for programme success awareness - is missing. It is therefore crucial to evaluate children's awareness when conducting a metacognitive training such as GMT. To our knowledge there is a lack of self-awareness measures for children. Tools used in metacognition developmental research [44] [17] [45] [21] are not easily accessible or transferable to the context of rehabilitation (e.g.: use of event-related potentials)[44]. Furthermore, as cognitive rehabilitation of EF aims at understanding and improving daily life executive functioning in the natural context of the child, classically used measures of metacognition (Judgments of Learning - JoL; Ease of Learning judgments - EoL; Feeling of Knowing - FoK; during a word list learning, in an office-based un-ecological environment [21][12][13][14] [15][16]) are not clinically useful.

6 Awareness pilot study, November 2014

URL: http:/mc.manuscriptcentral.com/dandr Email: davemuller@suffolk.ac.uk 
The primary aim of this pilot study was to examine the feasibility of three ways of assessing awareness of executive dysfunction in children with a TBI during a rehabilitation programme based on GMT.

\section{METHODS}

This awareness study was part of a pilot study that tested an intervention based on a contextsensitive pediatric Goal Management Training (GMT) combined with ecological activity practice. Details and effectiveness of the intervention are reported elsewhere [38]. Children were taught metacognitive strategy use through discussion of stories in which story characters experience cognitive failures. Children were introduced to ideas of how those may be prevented, and were given practice at applying metacognitive strategies on paper-and-pencil exercises, then on ecological activities in the rehabilitation centre, and finally on real life activities at home and school. The programme used a range of functional, meaningful activities including cooking. The training was administered weekly, for 15-20 hours over 4-6 months. Because of the availability and time required by the intervention for the children included in this pilot study, it was not judged ethically possible to include typically developing children. Children included in the study had sustained a severe TBI at least two years earlier, had a documented dysexecutive syndrome, including executive functioning difficulties in daily life as reported by parents and school staff.

Awareness was assessed using three different measures: two measures of metacognitive knowledge (intellectual awareness) and one measure of on-line/emergent awareness.

The two measures of metacognitive knowledge (MK) corresponded to two different levels of Crosson's intellectual awareness (see figure 1). The first measure assessed level (a) of Crosson's intellectual awareness i.e. the basic understanding that a deficit exists. The second measure assessed levels (b) and (c) of Crosson's intellectual awareness i.e. (b) the recognition of a common thread in the activities the patient is impaired in and (c) the implications this has.

7 Awareness pilot study, November 2014

URL: http:/mc.manuscriptcentral.com/dandr Email: davemuller@suffolk.ac.uk 
The first measure of MK (the basic understanding that a deficit exists) consisted of a discrepancy score using the "goal management training questionnaire"[40] translated into French, simplified and adapted for children (see appendix 1). This questionnaire, based on the adult GMT questionnaire, is specific to goal management difficulties and 'goal neglect' (failure to take actions to achieve goals despite the intention to do so). It is however not validated and has no norms. Because poor reading skills and vocabulary might have influenced children's responses, the questions were read to the child who answered orally. The questionnaire presents common executive failures that can happen at home, at school or during leisure activities (e.g. "Forgetting something that needed to be done at a certain time, running out of time because you got too caught up in something that you were doing, starting an exercise and realising once you've started that are not doing what was asked..."). For each of the 30 items of the questionnaire, the child had to report if the item was a problem for him/her. The questionnaire was answered during an interview with the child without his/her parents, before the intervention. The trainer provided age-appropriate examples for the items the child did not understand spontaneously. At the end of the intervention the same person who trained the child throughout the rehabilitation programme, answered the questionnaire as well, based on what she witnessed of the child's behavior during the intervention and based on contacts with parents and school. As the trainer had spent 15-20 hours with the child, it allowed her to observe carefully the child's functioning. The questionnaire score of MK awareness was obtained similarity to the KIC[9], from the number of discrepant items between the child's rating of the questionnaire and the rating of the trainer. An item was judged as discrepant if the child responded it was not a problem, or a minor problem but the investigator thought it was a significant problem, obtaining a binary response for each item (aware/unaware). Potentially inversed discrepancies (the child thinking an item was problematic while the trainer responded it wasn't) did not occur. Items not relevant (e.g. forgetting books in the school bag, when school bag is not prepared by the child) were excluded, as well as items the examiner could not judge reliably at the end of the intervention. The final score was a percentage of "unaware items" divided by the number of relevant and reliable items.

8 Awareness pilot study, November 2014

URL: http:/mc.manuscriptcentral.com/dandr Email: davemuller@suffolk.ac.uk 
The second measure of MK (the recognition of a common thread in the activities in which the patient is impaired and the implications this has) used stories contained in the pediatric GMT intervention[38], and was assessed throughout the intervention. In these stories, characters have a series of daily life problems related to their executive dysfunction (e.g. putting an essay to hand in at school into a sports bag instead of a school bag). Stories are age-appropriate and consequences of the problems are emphasized (e.g. stress while looking in the school bag for the essay, feeling upset when finding the essay in the evening while getting dressed for football, getting a lower mark because the essay was handed in late...), as well as factors that contributed to the problem (e.g.: going to bed late because writing the essay at the last minute, being in a rush when preparing the school bag and the sports bag the next day). Use of PowerPoint slides with child friendly drawings, allowed children to follow the story without too much pressure on their working memory. The intervention contained a total of six stories, one every two weeks. At the end of each story, the child was asked "Do you think this could happen to you?" and it was followed by a discussion with the child about personal examples of cognitive failures and slips (called "Oops errors" in the intervention), implications and factors that contributed to these "Oops errors", and similarities with the stories. The awareness deficit score was the percentage of stories the child thought would never happen to him/her, while the trainer saw similar events regularly happening to the child, divided by the total number of stories. A child who acknowledged that this kind of story could have happened to him/her, but could not provide any personal examples of similar cognitive failures, was still considered as being aware on that story (i.e. providing personal examples was not mandatory to score as aware on a story).

Emergent (i.e. on-line) awareness was assessed throughout the intervention by asking the child at the end of each session if s/he thought the exercise/activity had been difficult for him/her. Exercises could be office-set paper-and-pencil school type exercises or complex daily life tasks like real cooking. An awareness deficit was taken as a percentage of activities judged by the child as easy while $s /$ he completely failed or required a lot of help to achieve the goal, divided by the total number

9 Awareness pilot study, November 2014

URL: http:/mc.manuscriptcentral.com/dandr Email: davemuller@suffolk.ac.uk 
of intervention sessions. On-line awareness assessment was conducted throughout the training, at the end of each session, with a total of 15 sessions. Children were also asked to identify "Oops errors" (cognitive slips) s/he had made during the exercise/activity, to qualitatively assess their online awareness.

Because awareness measures (except the questionnaire) were embodied in the intervention program, throughout the $15-20$ hours of training, it was not possible to obtain data from healthy controls who did not follow the intervention on those specific awareness measures.

Although this was not intended to be part of the awareness assessment, we also report here the behavior of children during a pre-intervention test using cooking, the Children's Cooking Task[46] [47] (CCT). In the CCT, children have to make a chocolate cake following a child-friendly photo-cued recipe. Children repeated the test twice before the intervention (to obtain two baselines). Children were not asked about their performance on the CCT because it would have acted as a cue for subsequent CCT assessments. However as behavior gave the trainer some insight into children's online awareness through error detection on task, and possibly anticipatory awareness on the second attempt to make a chocolate cake (for second baseline), trainer qualitative observations are reported.

\section{RESULTS}

Five children were initially included in the study. One child (YR) dropped out after four sessions.

Children's detailed medical history, neuropsychological assessments and overall intervention effect can be found in table 1. All children suffered a severe dysexecutive syndrome, especially on ecological measures of executive functions (Children's Cooking Task and questionnaires). Neuropsychological assessment showed relatively preserved or even normal episodic memory (see table 1- except for RK, in story recall which was poor probably due to attention rather than memory 
problems) therefore high anosognosia scores in the stories and questionnaire did not reflect a memory problem.

\section{Insert Table 1 about here}

\section{FEASABILITY}

Our method of awareness assessment showed good feasibility. For the first measure of MK, all children were able to understand the thirty-one items of the questionnaire when provided with examples. The maximum number of items per child the trainer could not reliably assess at the end of the intervention was two. For the second measure of MK (stories), children enjoyed GMT stories and could understand them easily. All stories could have happened to the children and were relevant. Children could identify no "Oops errors" in activities they had judged as easy, even when they had failed the task.

\section{AWARENESS SCORES}

Awareness deficit scores for each type of awareness are presented in figure 2. Higher scores indicate that children are more anosognosic/unaware, i.e. representing a deficit in awareness. Lower scores reflect better awareness.

\section{Insert Fig 2 about here}

\section{QUALITATIVE DATA}

\section{CHILD 1: YR}

YR was 14. He had sustained a severe TBI at the age of 2.5 years (collision with a running child); he attended a special school but was excluded from school for half of the year for behavioral issues. YR dropped out from the intervention after 4 sessions.

11 Awareness pilot study, November 2014

URL: http:/mc.manuscriptcentral.com/dandr Email: davemuller@suffolk.ac.uk 
YR reported none of the questionnaire items as problematic, despite having been observed making frequent errors, resulting in a $100 \%$ awareness deficit score. As for pGMT stories of the modules he completed before he dropped out of the study (4), YR thought the characters must be "stupid" and such cognitive failures would never happen to him and never gave any example of personal "Oops errors" in the story discussion, nor did he acknowledged he made mistakes or errors in the ecological intervention activities. An example is his performance on the CCT (Children's Cooking Task) prior to the intervention: YR found the correct recipe easily, took a quick look at the ingredients needed, put all the eggs he could find on the table, all the baking powder (5 packets), added one spoon of chocolate and one spoon of flour and put it in the oven. At the end of the task, both the child and the examiner tasted the "chocolate cake" that was rather a baking powder-flavored omelet, provoking instantaneous tingling in the mouth. YR said: “I didn't know it was so easy to make a chocolate cake. But next time I'll put slightly more chocolate" and wanted to eat the remaining cake. After being shown that on the same page there were stepwise instructions and asked if he thought he had followed them, YR looked perplexed for a moment and said in a defensive voice “No, I didn't but I've managed well anyway". YR made it clear he was not interested in the training and that he needed no help. However he was very interested in the module that explained executive function impairment and spontaneously admitted "That's exactly my problem", suggesting some intellectual awareness but then returned to a contemptuous attitude for the training. Before he dropped out of the study, YR participated actively in the sessions, while affirming he participated only because his parents forced him and that he had no need for it.

CHILD 2: PB

$\mathrm{PB}$ was 11. She was a passenger in a motor-vehicle accident at the age of 2.5 years with severe brain lesions requiring immediate neurosurgical treatment. She attended mainstream school with a parttime school assistant. She had epilepsy absences treated by carbamazepine. PB was intellectually aware of her impairment on nearly all items of the questionnaire. Indeed, she understood she had

12 Awareness pilot study, November 2014

URL: http:/mc.manuscriptcentral.com/dandr Email: davemuller@suffolk.ac.uk 
difficulties with some activities, (lowest level of Crosson's intellectual awareness) and answered to most items in the questionnaire as "big, big problem for me", but she seemed unable to understand the implications of her deficits (highest level of intellectual awareness). While enjoying the GMT stories very much (our second measure of MK), PB never acknowledged such things could happen to her. For example, she recognized she often forgets and loses important objects (at school, she is late half of the time because she realizes on her way to school that she didn't take her schoolbag; she doesn't give forms to be signed by parents to her mother, who then misses important school meetings). However these situations did not seem problematic to PB, and there was no emotional reaction when these failures were discussed in relation to the stories. PB regularly took examples of her highly organized mother's rare executive failures as an excuse for her own frequent failures: "My Mum sometimes forgets her bag as well". As for on-line awareness, she judged most of the activities as easy, even when she needed considerable help to manage them. She never recognized she failed an activity and it was thus impossible to convince her that the training could help her. In the CCT, on her first attempt to make a chocolate cake she forgot the baking powder. On her second attempt, she focused on not repeating the same error and managed a beautiful looking cake, containing the baking powder, but this time missing sugar. While still unable to acknowledge the need to compensate for EF dysfunction at post-intervention testing, she was reported to have made significant progress on parental and teacher post-intervention questionnaires (see [38]) and parents were highly satisfied with the intervention, reporting that she understood her brain functioning better.

CHILD 3: CS

CS was 11. She had sustained a TBI when a soccer goal post fell on her head at the age of 6.5 years, with mainly cerebellar and right parieto-occipital lesions. She attended a special school and a mainstream school part-time. Her intellectual quotient was on the lower limit of normal and she had impaired theory of mind and language pragmatics described in her previous rehabilitation reports. CS

13 Awareness pilot study, November 2014

URL: http:/mc.manuscriptcentral.com/dandr Email: davemuller@suffolk.ac.uk 
was aware of most problematic items of the questionnaire i.e. basic intellectual awareness. In our second measure of MK (stories), CS acknowledged all of them could have happened to her. However her behaviour indicated that she often simply "guessed" that she was expected to say "yes, that story could have happened to me" and she could not provide any personal example of a similar "Oops error" in the discussion that followed the stories. She couldn't evaluate her performance "online" during or after activities, did not express awareness of "Oops errors" after the tasks and always thought activities were easy and that she did well, although she failed or needed much help on most tasks.

CHILD 4: IP

IP was 8 at the beginning of the training. A television had fallen on his head at the age of 5.5 years. He attended mainstream school with a part-time school assistant. He was diagnosed with ADHD, with symptoms that had probably started prior to the TBI. Very protected by his carers, who confronted him as little as possible with his difficulties (e.g.: managing his schoolbag preparation), he had few opportunities to notice that he was impaired and lacked knowledge about the consequences of his TBI. All three measures of awareness showed a moderate awareness deficit, with highest unawareness for on-line awareness. Very few examples of personal "Oops errors" could be obtained from IP and most of these were not appropriate. On his first attempt to make the chocolate cake, he used a small coffee bowl instead of the required salad bowl: after pouring in the sugar, the bowl was full, however he continued adding the other ingredients until the bowl was invisible and totally covered under a mountain of flour. He showed no manifestation of having detected this error and was very surprised when he looked at the photo of the next step of the recipe, depicting a half full salad bowl of cake mixture. He also had difficulty following the recipe steps and missed the step requiring to stir the mixture until it was smooth. He was very surprised that, once cooked, the "cake" had separated into white-flour and a black-oily layer. During training sessions, he alternated from great overestimations of his abilities ("I'm the most intelligent boy of my class, this exercise is just

14 Awareness pilot study, November 2014

URL: http:/mc.manuscriptcentral.com/dandr Email: davemuller@suffolk.ac.uk 
too easy") to deep self-depreciation ("I can't do it because I'm just too stupid") and presented great emotional reactions to his performance, including inconsolable crying when he was failing a cooking recipe, inappropriate laughing, and rolling on the floor when he could not find a solution to a problem.

CHILD 5: RK

RK was 13 . He had sustained a motor-vehicle pedestrian accident at the age of 7 . He attended part time private schooling with school assistant part time private lessons. He presented with severe attention problems. Although 13 at the time of the study, his parents could never leave him at home alone, he was forbidden to enter the kitchen as he usually forgot to switch off the gas. RK was fully aware of his impairments on all three measures. He is the only child who actually acknowledged the utility of strategies taught during the intervention and used them to compensate for EF dysfunction post-intervention. However effects did not transfer to natural contexts and no change was reported by parents on post-intervention questionnaires [38]. However he seemed unaware of his lack of cognitive flexibility. This was illustrated by a cooking episode at home reported by his parents. He decided to make finger biscuits (that he had practiced during the intervention) for his large family. He decided to multiply all ingredients by 5 (which would give over one hundred biscuits), because it would require 500 grams of butter which is the usual size of butter packs found in shops. His parents tried to persuade him that this would be too much and that multiplying recipe quantities by two would suffice. He could not accept it, even though there was no problem with mathematical skills and he refused to make the biscuits at home with any other quantity. A whole intervention session focused on this problem without success.

\section{DISCUSSION}

All three methods of awareness assessment showed good feasibility. Apart for one child who presented complete anosognosia on all awareness measures (YR), children showed relatively 
preserved basic intellectual awareness but more difficulty in the higher order intellectual awareness and on-line awareness. Observation of the cooking activity on the CCT allowed an interesting insight into the children's awareness and especially error detection.

\section{MEASURING METACOGNITIVE KNOWLEDGE/ INTELLECTUAL AWARENESS}

Many ways of assessing awareness in adults have been described in the literature (see Ownsworth and Clare [48] for a review). Intellectual awareness is commonly assessed through discrepancy scores between the patient and a significant other's rating on a questionnaire (e.g. Dysexecutive questionnaire[49], Patient Competency Rating Scale[50][51] , Awareness questionnaire[52]). Selfreport versus test performance is another way of assessing intellectual awareness. Our approach was a discrepancy score approach but was close to the self-report versus test performance approach, as the therapist was the informant, and most items judgments were based on children's actual behavior and performance throughout the sessions. The questionnaire was easily understood by all children and, as the informant was the therapist (taking into account interviews of parents and school staff), we probably managed to have a more objective informant report than when parents answer questionnaires alone. However, the questionnaire was long and items related to the content of the intervention (Context-sensitive Goal Management Training[38]), that focused on improving executive functions and prospective memory. This questionnaire would need to be shortened and simplified further if applied to cognitive rehabilitation outside GMT training context.

Crosson's levels of intellectual awareness proved useful in explaining PB's dissociated intellectual awareness: excellent awareness of impairments on the questionnaire (lower level of intellectual awareness) but difficulty in recognizing common threads between activities she is impaired in (on the GMT stories) and total unawareness of the consequences of these impairments (highest level of intellectual awareness) when these were discussed during training sessions. The difference between the two levels of intellectual awareness described by Crosson: (1) knowledge of impairment and (2) implications of impairment is probably a key issue in research with children. PB could state her 
impairments well, but did not see the implications of them - and thus did not acknowledge the need to compensate for them.

The GMT stories offered the advantage of presenting to the child both impairment and its consequences in an accessible story, with a visual support that lowers working memory and language demands. Through these stories of daily living, we hoped the child would understand the cognitive failure and its consequences and use it to recognize how cognitive failures may impact on home, school and leisure activities. Children found the stories fun and understood them easily, as opposed to more general questions that have been used to assess intellectual awareness in children [31][35]. However, this approach for assessment of awareness requires intact theory of mind (ToM) skills. First level ToM is needed to adequately understand how the character thinks and feels in relation to the situation. Second level ToM is needed to understand what the character thinks the surrounding characters are thinking (e.g. a story where a boy forgets the ball he was supposed to take to a football match with his friends, who become angry with him). Unfortunately we did not assess ToM in participants, nor did we ask control questions to check if the children had sufficient ToM ability to fully understand how the character is feeling. As children who sustain a TBI can suffer impaired ToM [53][54], such an assessment should control for ToM. A way to control for ToM would be to ask the child how the character is feeling instead of including this information in the text of the story. For example CS, who was described in her medical reports as having poor ToM, had difficulty understanding the stories. She could not give personal examples of similar events, and struggled to understand how the reaction of characters in the story related to cognitive failures. She also did not appear to be aware of the consequences of the cognitive slips. However, she often answered that "yes that story could have happened to me", relying on her knowledge that she often does things wrong and she simply "guessed" what she was expected to say. Therefore her story score seemed unrealistically good and therefore unreliable, probably because of her reasoning and ToM impairment. ToM has shown to be correlated to self-awareness [55] in adults and must be assessed if stories are used to assess metacognition. On the other hand, some authors proposed that 
metacognition and awareness reflect ToM about one's own thoughts [56][57], and that both rely on the same cognitive ability and common brain structures[58]. Another problem with using stories to assess awareness is that the measures can be biased by children's incapacity to generalize the situations presented to other similar situations where the same cognitive failure can occur.

\section{ON-LINE AWARENESS}

MEASURING ON-LINE AWARENESS

On-line awareness is difficult to assess. In the literature several approaches have been described: (1) think aloud protocols (the child is told to say aloud everything he/she is thinking [59]; (2) video analysis of performance where the examiner looks for signs of error detection (verbalization, non word exclamation such as "oops!", facial expressions, head-shaking, manual gestures) in the patients behavior[60]; (3) forced on-task verbalization of error detection (e.g: patient instructed to say "hit" whenever he/she notices that he/she made an error)[8]; (4) event-related potential examination during task [61]. Think aloud and forced on task-verbalizations are problematic in that they inevitably become a dual task paradigm and/or a prospective memory task: They require additional attention allocation to the task of showing the examiner an error has been detected. Furthermore in both these approaches, as the patient is informed of being assessed/watched on his/her error detection skills, s/he is likely to focus on error detection rather than the task itself, and as a consequence provides an unecological (and thus inaccurate) measure of error detection capacity in daily tasks. Conversely, behavioral signs of error detection probably underestimate error detection, as very early detected errors and errors with little consequences are unlikely to be expressed by overt behavior, especially if the patient wants to appear successful. Event-related potential (ERP) offers an alternative way of assessing error detection[44]. Following an error, an error-related negativity is registered, that has been argued to correspond to the unconscious (implicit) error detection, whereas conscious errors are followed by a positive deflexion [44]. This post-error positivity is

18 Awareness pilot study, November 2014

URL: http:/mc.manuscriptcentral.com/dandr Email: davemuller@suffolk.ac.uk 
reliably associated with decreased on-line awareness of deficits [62] and was proposed as an electrophysiological indicator of on-line awareness in adults. ERP studies suggest that a child may have no experience of making an error, either because s/he truly does not detect errors, or because implicitly detected errors are not brought to consciousness. From a rehabilitation point of view, it has consequences as to where to focus intervention: it seems illogical to try and make children consciously aware of errors they haven't detected "electrophysiologically", at a basic, unconscious level. From a developmental point of view, it is interesting to note that the error-related negativity that follows all errors (conscious or not) has been shown to increase with age, whereas the subsequent positive deflexion (present only for conscious errors) - marker of on-line awareness -, is stable with age. Although theoretically promising, ERPs are impractical to use during rehabilitation sessions and will probably remain a research tool rather than being used routinely for clinical purposes.

TRULY “ON LINE" VERSUS “OFF-LINE" AWARENESS: PREDICTION AND EVALUATION OF TASK PERFORMANCE

In our study we tried to find a way of assessing on-line awareness, without disrupting the ongoing task. Our measure of on-line awareness (responses to the broad question "Was the task difficult for you?" and post-task error recollection) had the drawback of requiring preserved memory of performance, as children were asked the question only after the task. It relied on post-task evaluation, rather than "truly on-line" error detection and was therefore rather a measure of "offline" awareness. The term "off-line " metacognition/awareness has been proposed by Desoete [17] in her study of metacognition in math problem-solving. Off-line metacognition includes both prediction (of difficulty, of time required to complete the task) and post-task evaluation of performance. Emergent/on-line awareness can be considered to comprise truly "on-line" awareness (error detection, monitoring of performance during the task) and off-line awareness (immediately before and after a task). Off-line is included in on-line awareness because it is activated within the 19 Awareness pilot study, November 2014 URL: http:/mc.manuscriptcentral.com/dandr Email: davemuller@suffolk.ac.uk 
context of a specific situation or task and involves judgments about one's abilities and limitations in relation to the current situation. Furthermore a complex task such as cooking is a series of subtasks and therefore predictions, error detection and monitoring and evaluation are continuously needed throughout the task: as such off-line awareness is needed throughout the task.

PREDICTION OF PERFORMANCE AND ANTICIPATORY AWARENESS

The exact distinction between prediction of performance and anticipatory awareness is unclear in the literature and therefore the two terms are sometimes used interchangeably. Our view is that prediction of performance is a skill, which can be prompted and is cognitive in essence. Anticipatory awareness is the behaviour that results from spontaneous, correct prediction of task difficulty and of self-capacity to deal with the task. Anticipatory awareness is very difficult to capture in an assessment because it is a behaviour rather than a measurable cognitive function. Anticipatory awareness is expressed when the potential for a problematic situation/task arises in daily life. All attempts to capture anticipatory awareness in an office-based interview or assessment are unecological, because asking the patients how they perceive their ability in a hypothetical situation provides a prompt for awareness and assesses intention of behaviour. It does not reflect actual behaviour in such a situation, in daily life, and in the patient's usual environment. Most assessments termed "anticipatory awareness" assessments are really "off-line" prediction awareness measures (e.g.: asking the patients : "how do you think your performance on the task might affect your ability to live independently, work and have fun?" [6]; or predicting memory span[8]).

In our study, none of the three measures of awareness served to assess prediction or anticipatory awareness. However qualitative observation of children's behaviour gave some insight into their anticipatory awareness, especially on their second attempt on the CCT. For example PB, who had only very basic intellectual awareness, could predict she might forget baking powder again and thus concentrated on adding the baking powder on the subsequent CCT attempt.

20 Awareness pilot study, November 2014

URL: http:/mc.manuscriptcentral.com/dandr Email: davemuller@suffolk.ac.uk 
Anticipatory awareness probably has different levels as suggested by PB: she could anticipate she would forget the baking-powder (lower level of anticipatory awareness, in this case "baking powderspecific"), but could not generalise this anticipatory awareness to other ingredients she might forget (higher level of anticipatory awareness, "ingredient-specific"), or to the anticipation that she may forget not only ingredients but whole recipe steps, switching on the oven (highest level of anticipatory awareness), or even more broadly that she is very disorganised irrespective of the type of task (generalised anticipatory awareness, in other activities such as cooking in general, do-ityourself, homework...).

DETECTING ERRORS ON-LINE AND ERRORLESS LEARNING

Another issue for our measure was the help given to children on the tasks. For unfamiliar tasks such as cooking, the considerable help provided by the trainer probably seemed natural to children and with the help received - the task might be perceived as "easy". On-line awareness can probably be experienced only if a patient is allowed to struggle on task, which was not the case during the intervention, as our first aim was to train children in novel complex task management, and only secondly to assess awareness. This issue is particularly important as some authors advocate errorless learning for patients with dysexecutive syndromes[39]. Classically, errorless learning has been used in patients with memory deficits: Errorless learning is based on the assumption that explicit memory for errors is impaired, whereas implicit memory is not, meaning that errors are primed, and so are more likely to be repeated. In errorless learning instructions, the aim is to try to prevent patients from making errors during the learning process. However it has also been proposed to use errorless learning in patients with a dysexecutive syndrome without memory deficits. In those patients, errorless learning is based on the assumption that the error-monitoring system is defective [63][64], whereas implicit memory is not, yielding a memorisation of the undetected error. In errorless learning patients are not given the opportunity to detect their errors because errors are prevented by the therapist. It is possible therefore that this could impair the development of on-line awareness

21 Awareness pilot study, November 2014

URL: http:/mc.manuscriptcentral.com/dandr Email: davemuller@suffolk.ac.uk 
by ensuring success on tasks at all times and offering no opportunity for the error-monitoring system to be trained/used. Therefore error-based learning has been proposed to improve self regulation in adults with ABI[65]. Error-based learning may be useful in helping children to develop their on-line awareness through error detection, but this must be considered carefully and evaluated for children with severe episodic memory impairments, who may not remember the error they detected and therefore may profit more of an errorless learning approach. It would be interesting to include an assessment of awareness (and especially on-line awareness) in trials comparing errorless and errorbased learning.

STEPS REQUIRED FOR CORRECT POST-TASK EVALUATION

Post-task evaluation was influenced by different factors in our study, and not only error detection ability. Qualitative analysis of on-line awareness measures, based on the performance of the five children on the ecological training activities and on the Children's Cooking Task lead us to propose a series of steps necessary for adequate post-task evaluation, (where error detection is only the first step). Figure 3 presents examples of children's (real or hypothetical) verbalisation for each step, corresponding to a situation where the child is aware. In our view, a child must go through all the steps to truly experience the difficulty of having trouble with a task (i.e. on-line awareness). We suggest that to understand a child's on-line awareness deficit in rehabilitation, each required step should be assessed separately (see bottom line questions in figure 3).

\section{Insert Fig 3 about here}

The consecutive steps are: (1) Errors must be detected and brought to consciousness (see previous section on measuring on-line awareness); (2) Even if the error has been consciously detected ontasks, a child may have no memory of having performed poorly on the task because of episodic memory impairment (she/he does not encode performance on the task in episodic memory or does not encode it as an error or cannot access the memory). Even if an error is detected and

22 Awareness pilot study, November 2014

URL: http:/mc.manuscriptcentral.com/dandr Email: davemuller@suffolk.ac.uk 
remembered after the task, children may (3) not appraise the consequences/implications of the errors and therefore not interpret them as errors (errors with little consequences, or unknown consequences or corrected errors not being considered as errors) resulting in a very positive selfevaluation of performance; (4) neglect the main goal of the task. These last two factors are probably extremely important in children, as they tend to focus on things that went right or that were fun, rather than on errors which are thought of as minor details. All children had so much fun trying to make a chocolate cake in the CCT, that even totally failed cakes were given a positive appreciation by the child who made them: IP did not know that not mixing the liquid and the flour would result in an inedible cake. He could not make a connection between the cake consistency and his omission of mixing the ingredients (erroneous appraisal of consequences of the error). YR was pleased with his 'baking-powder omelette', although he acknowledged he was supposed to follow the recipe steps to make a chocolate cake (neglect of main goal); (5) For some children, in spite of adequate recognition of within-task errors, there is an inability to relate these apparently unique errors to previous similar experiences, nor to anticipate potential future situations where the same problems are likely to occur, impeding the child to generalize his/her on-line experience.

It is worth noting that a child's evaluation of his/her performance may be biased by some form of denial (i.e. the child detects, remembers, correctly appraises the consequences and places them in the context of the task goal but denies the error occurred, has consequences). Pure denial is rare in children[11] but is often the explanation for behaviour that might in fact be caused by awareness deficits [11]. In Beardmore et al. Study [9], emotionally-motivated or defensive denial (operationalised as a negative/avoidant coping style) was not supported as a contributor to the child's poor metacognitve knowledge.

THEORY OF AUTOBIOGRAPICAL METACOGNITIVE KNOWLEDGE ACQUISITION BASED ON ON-LINE EXPERIENCES

23 Awareness pilot study, November 2014

URL: http:/mc.manuscriptcentral.com/dandr Email: davemuller@suffolk.ac.uk 
We hypothesize that metacognitive knowledge is constructed from on-line awareness experiences, that will progressively allow the child to construct a sense of his/her own cognitive abilities, through the construction of semantic and autobiographical memories of task performance and difficulties. In the same way that children's development of autobiographical memory [66] is related to the understanding of their own mental states in the past [67][68], we postulate that self-awareness is related to the memory and understanding of on-line awareness experiences in the past.

Let's first take the simpler case of an adult. Dirette [69] suggests that awareness of cognitive deficits develops through "aha" moments, particularly in functional activities (e.g. being aware that one cannot drive from the actual experience of driving, rather than having been told you cannot drive) and familiar places (cooking at home rather than in the rehabilitation centre). When an adult is told that $\mathrm{s} /$ he is not able to drive, $\mathrm{s} /$ he may gain some general self-knowledge about his/her driving capacity, however this will remain a very theoretical knowledge, which we will call "semantic" metacognitive knowledge (MK). To be truly aware of his/her driving difficulty, s/he needs his/her own experience of performing poorly in driving, with preserved on-line awareness of making errors to support self-appraisal of driving capacity. If on-line awareness is intact, it is the actual experience of being conscious of driving dangerously that will allow him/her to truly internalise knowledge of his/her driving abilities, make it his/her own, store the "trying to drive" episode in his/her autobiographical memory and acquire MK that has "autobiographical" characteristics, including the phenomenological details accompanying the experience of having difficulty on the task (e.g. feeling anxious, hearing the horns).

Young children acquire most MK from adult reminders and feedback ("put it in your schoolbag or you'll forget it", "you're very disorganised"). Eventually a child who has been told for years that s/he is disorganized (like PB in our study), will acknowledge s/he is, gaining some basic semantic intellectual awareness (or semantic MK), by storing the information "I am very disorganised" in

24 Awareness pilot study, November 2014

URL: http:/mc.manuscriptcentral.com/dandr Email: davemuller@suffolk.ac.uk 
his/her semantic memory. However this semantic MK will remain a fact, without a link to an episodic sense of self.

From a developmental point of view, semantic MK precedes on-line awareness [2]. With age, children become increasingly conscious of cognitive capacities, strategies for processing information, and task variables that influence performance [70] and have more attentional resources to devote to on-line monitoring/error detection. As on-line monitoring skill becomes more efficient, children's online awareness increases and allows them to be aware of having difficulty with a certain task (following the steps described in the previous section). Progressively, memories of correctly appraised performance are stored in memory resulting in increased MK, that does not rely solely on what the child knows because s/he has been told by his/her parents (basic semantic MK) but on his/her own experience, with all the phenomenological details accompanying this experience (e.g. feeling anxious when realising school bag is missing, smelling the burnt cake). Therefore the memories of these correctly appraised experiences, which the child will truly remember, will allow full awareness (comprising both semantic and autobiographical components) and will hopefully be retrieved and used to anticipate future problems (anticipatory awareness) in similar situations (see figure 4). However, because autobiographical memory matures gradually throughout childhood [66], a unique experience of failure will probably not be stored or retrieved as clearly as in adults. Children may recall for example that they enjoyed cooking, and what they managed well, rather than remembering their difficulties in planning on-task and the strategies they used to overcome difficulties.

\section{Insert Fig 4 about here}

Conversely, for younger children, most MK will be gained from external information and their MK will essentially rely on the "semantic" awareness (see fig 4). In our view autobiographical MK/intellectual awareness develops gradually, along with the development of autobiographical memories, and young children should not be expected to have complete intellectual awareness. However it is worth 
noting that younger children may still exhibit anticipatory awareness, based on their semantic MK:

They may not have lived the experience of being impaired (or developmentally immature) on a task, but may rely on what their parents taught them ("don't cross the street on your own") and on their semantic general memory (e.g.: children don't drive cars).

Our theory could explain the dissociation in the MK scores in the discrepancy questionnaire score and GMT stories. The questionnaire assessed basic knowledge of functioning, which can be qualified as the "semantic" MK/ intellectual awareness about self and was probably mainly acquired by repetitive comments of adults (parents, teachers...). Stories on the other hand, especially when they elicited pertinent examples of personal cognitive failures in the autobiographical memory, relied more on autobiographic $\mathrm{MK} /$ intellectual awareness, by cueing the children on consequences of the cognitive failures and phenomenological details developed in the story (how the character felt, what were the circumstances... ).

\section{FACTORS CONTRIBUTING TO POOR AWARNESS IN CHILDREN}

It is often said that 'It takes a whole life to know oneself', reflecting that even for adults, being fully aware of one's strengths and weaknesses is challenging. Children with brain injury might have specific deficits that impact on their functioning, but these are set in the context of (1) having cognitive functions that are constantly developing, (2) being supported by parents, teachers and others to carry out new tasks (so not necessarily having the experience of difficulties) and (3) having limited attentional/executive resources that make monitoring and reflecting on performance difficult [70]. Thus it might be said that being self-aware is a challenge for everybody, but for children it is particularly difficult and hence for children with brain injury it is major problem [9].

In our study, children's awareness was influenced by many factors. For the youngest (IP), a lack of knowledge about his impairments due to a lack of confrontation probably explained much of his unawareness. Reassurance and help from parents assured success on tasks but also contributed to

26 Awareness pilot study, November 2014

URL: http:/mc.manuscriptcentral.com/dandr Email: davemuller@suffolk.ac.uk 
his lack of awareness. However IP's emotional responses to failures, suggest that such a nonconfrontational reassurance may not be appropriate, even for children as young as 8 . Another factor is the type of activities children are confronted with: for most children, it appeared obvious that they would be given help if they attempted to cook a cake and therefore judged the task easy, because adult help was inherent to the task at their age. For YR, part of his unawareness was probably due to a denial of his impairment or at least a wish to hide any difficulty.

Awareness is probably easier to gain for some cognitive functions than others, and from our data, cognitive flexibility seemed to be the most difficult cognitive function to gain awareness of. This was illustrated by RK who showed excellent awareness on all measures, who frequently talked about his memory and planning difficulties, but who could not acknowledge his cognitive rigidity.

Questionnaires and stories did not include aspects of cognitive flexibility and it would be a valuable addition for further development of awareness assessments in both children and adults. For example, it would be interesting to see whether RK would react to a story where a character shows a difficulty with cognitive flexibility (such as RK's own relating to quantity of cooking ingredients). However being aware of one's own cognitive rigidity and detecting it on task is, in itself, something that requires cognitive flexibility; therefore awareness of cognitive flexibility deficit is probably, by definition, incompatible with such a deficit.

\section{LIMITATIONS AND RECOMMENDATIONS}

It is not possible to determine from our data if the children had more impaired awareness than healthy children, as we did not include healthy controls with whom to compare awareness scores. Developmental studies are needed to explore awareness in healthy children, without which literature lacks a reference to normative standards and degree of awareness impairment in our clients who suffered a TBI cannot be precisely determined.

27 Awareness pilot study, November 2014

URL: http:/mc.manuscriptcentral.com/dandr Email: davemuller@suffolk.ac.uk 
Awareness is multicomponential, and different components have different importance depending on the child's age (e.g. autobiographic awareness is not expected before late childhood/adolescence). Each component should be assessed separately to truly understand where the child's foundation of unawareness deficit lies.

\section{Insert Fig 5 about here}

Figure 5 summarises the awareness components that are easily measurable separately. Real cooking seems a feasible, fun and ecologically valid way for studying on-line awareness (please refer also to figure 3). Prediction and evaluation are important to assess but also to practice and should be included during activities at school and at home (refer to Ylvisaker [11] for details). For intellectual awareness, stories seem a particularly well-suited assessment because (1) children find them fun; (2) children understand them easily; (3) drawings lower working memory demands; (4) consequences and factors contributing to cognitive failures can be included in the story and elicit awareness of them. The story format however does not appear to be appropriate for children with severe reasoning or ToM deficits. Brain storming about personal examples of cognitive failures elicited by stories (or by another support including questionnaires) allows one to determine whether children rely on semantic awareness, autobiographical awareness or both for their responses. The remember/know paradigm and explicit requirement to provide phenomenological details can be used to differentiate between autobiographical and semantic awareness (see [66][71] for details about the paradigm referring to autobiographical memory). Assessing anticipatory awareness remains a challenge but is most likely to be valid during ecological activities at home, school or during rehabilitation activities using real life settings and activities such as cooking, without prompting and without explicit knowledge of the child of being assessed.

So far metacognition in children has been mostly explored in meta-memory research. As EF are the main problem for independent daily living, "meta-EF" studies (and especially “meta-EF" in ecological settings) are urgently required before engaging children and teams in clinical and research 
programmes of metacognitive strategy training that rely on awareness, which may be recommended

for adults but whose appropriateness for different stages in childhood are not yet established.

\section{DECLARATION OF INTERESTS}

The authors report no conflicts of interest. This study was supported by scholarships, from the "SOFMER" (French Society of Physical and Rehabilitation Medicine), the "SFERHE" (French Research Society against Children's handicap) and the "Fondation Gueules Cassées". Results of this work were presented at the joined 29th SOFMER - 19th ESPRM congress in Marseille in May 2014.

\section{REFERENCES}

1. Hacker DJ. Definitions and empirical foundations. In: Metacognition in educational theory and practice. Vol. xiv. The educational psychology series. Mahwah, NJ, US: Lawrence Erlbaum Associates Publishers; 1998.

2. Flavell JH. Metacognition and cognitive monitoring: A new area of cognitive-developmental inquiry. American Psychologist. 1979;34:906-911.

3. Fleming JM, Ownsworth T. A Review of Awareness Interventions in Brain Injury Rehabilitation. Neuropsychological Rehabilitation. 2006;16:474-500.

4. Crosson B, Barco PP, Velozo CA, Bolesta MM, et al. Awareness and compensation in postacute head injury rehabilitation. The Journal of Head Trauma Rehabilitation. 1989;4:46-54.

5. Toglia J, Kirk U. Understanding Awareness Deficits Following Brain Injury. NeuroRehabilitation. 2000;15:57-70.

6. Abreu BC, Seale G, Scheibel RS, Huddleston N, Zhang L, Ottenbacher KJ. Levels of self-awareness after acute brain injury: How patients' and rehabilitation specialists' perceptions compare. Archives of Physical Medicine and Rehabilitation. 2001 January [cited 2012 August 23];82:49-56.

7. Stuss DT. Disturbances of self-awarness after frontal system damage. In: Awareness of Deficit after Brain Injury: Clinical and Theoretical Issues. Oxford University Press. Oxford University Press; 1991.

8. O'Keeffe F, Dockree P, Moloney P, Carton S, Robertson IH. Awareness of deficits in traumatic brain injury: a multidimensional approach to assessing metacognitive knowledge and online-awareness. J Int Neuropsychol Soc. 2007 January;13:38-49.

9. Beardmore S. Does Information and Feedback Improve Children's Knowledge and Awareness of Deficits after Traumatic Brain Injury? Neuropsychological Rehabilitation. 1999 [cited 2013 August 21];9:45-62.

10. Jacobs MP. Limited understanding of deficit in children with brain dysfunction. Neuropsychological Rehabilitation. 1993 [cited 2014 April 29];3:341-365. 
11. Ylvisaker M ed. Cognitive Rehabilitation: Executive Functions: Self-Awarness. In: Traumatic brain injury rehabilitation: Children and adolescents (2nd ed.). Vol. xiv. Woburn, MA, US: ButterworthHeinemann; 1998. p 247.

12. Roebers CM, von der Linden N, Schneider W, Howie P. Children's metamemorial judgments in an event recall task. J Exp Child Psychol. 2007 June [cited 2012 August 22];97:117-137.

13. Hoffmann-Biencourt A, Lockl K, Schneider W, Ackerman R, Koriat A. Self-paced study time as a cue for recall predictions across school age. Br J Dev Psychol. 2010 November [cited 2012 August 22];28:767-784.

14. Koriat A. Easy comes, easy goes? The link between learning and remembering and its exploitation in metacognition. Mem Cognit. 2008 March [cited 2012 August 22];36:416-428.

15. Koriat A, Ackerman R, Lockl K, Schneider W. The memorizing effort heuristic in judgments of learning: A developmental perspective. Journal of Experimental Child Psychology. 2009 March [cited 2012 August 24];102:265-279.

16. Roebers $\mathrm{CM}$, Schmid C, Roderer T. Metacognitive monitoring and control processes involved in primary school children's test performance. Br J Educ Psychol. 2009 December [cited 2012 August 22];79:749-767.

17. Desoete A, Roeyers H, Buysse A. Metacognition and mathematical problem solving in grade 3. J Learn Disabil. 2001 October [cited 2012 August 21];34:435-449.

18. Borkowski JG, Estrada MT, Milstead M, Hale CA. General Problem-Solving Skills: Relations between Metacognition and Strategic Processing. Learning Disability Quarterly. 1989 [cited 2012 October 10];12:57.

19. Jacobs JE, Paris SG. Children's Metacognition About Reading: issues in Definition, Measurement, and Instruction. Educational Psychologist. 1987 [cited 2012 August 22];22:255-278.

20. Garrett AJ, Mazzocco MMM, Baker L. Development of the Metacognitive Skills of Prediction and Evaluation in Children With or Without Math Disability. Learn Disabil Res Pract. 2006 May 1 [cited 2013 December 18];21:77-88.

21. Nelson TO, Narens L. Metamemory: A theoretical framework and new findings. In: The psychology of learning and motivation. New York: Academic Press. G.H. Bower; 1990. pp 1-45.

22. Shimamura AP. The role of the prefrontal cortex in dynamic filtering. Psychobiology. 2000 June 1 [cited 2014 November 15];28:207-218.

23. Babikian T, Asarnow R. Neurocognitive outcomes and recovery after pediatric TBI: meta-analytic review of the literature. Neuropsychology. 2009 May [cited 2012 August 27];23:283-296.

24. Levin HS, Hanten G. Executive Functions After Traumatic Brain Injury in Children. Pediatric Neurology. 2005 August [cited 2012 August 27];33:79-93.

25. Anderson V. Assessing executive functions in children: biological, psychological, and developmental considerations. Developmental Neurorehabilitation. 2001 January [cited 2012 August 27];4:119-136. 
26. Delphine Viguier GD, Isabelle Gasquet, Claudine Martin, Marie Choquet. A psychological assessment of adolescent and young adult inpatients after traumatic brain injury. Brain Inj. 2001 January 1 [cited 2014 November 10];15:263-271.

27. Wilson KR, Donders J, Nguyen L. Self and parent ratings of executive functioning after adolescent traumatic brain injury. Rehabil Psychol. 2011 May [cited 2012 July 27];56:100-106.

28. Douglas JM. Using the La Trobe Communication Questionnaire to Measure Perceived Social Communication Ability in Adolescents With Traumatic Brain Injury. Brain Impairment. 2010;11:171182.

29. Wales L, Hawley C, Sidebotham P. How an occupational therapist should conceptualise selfawareness following traumatic brain injury in childhood - a literature review. The British Journal of Occupational Therapy. 2013 July 24;76:325-332.

30. Ornstein TJ, Levin HS, Chen S, Hanten G, Ewing-Cobbs L, Dennis M, Barnes M, Max JE, Logan GD, Schachar R. Performance monitoring in children following traumatic brain injury. J Child Psychol Psychiatry. 2009 April;50:506-513.

31. Josman N, Berney T, Jarus T. Performance of Children with and without Traumatic Brain Injury on the Contextual Memory Test (CMT). Phys Occup Ther Pediatr. 2000 January 1 [cited 2014 November 10];19:39-51.

32. Hanten G, Dennis M, Zhang L, Barnes M, Roberson G, Archibald J, Song J, Levin HS. Childhood head injury and metacognitive processes in language and memory. Dev Neuropsychol. 2004 [cited 2012 August 23];25:85-106.

33. Hanten G, Bartha M, Levin HS. Metacognition Following Pediatric Traumatic Brain Injury: A Preliminary Study. Developmental Neuropsychology. 2000 December 1 [cited 2014 November 11];18:383-398.

34. Crowther JE, Hanten G, Li X, Dennis M, Chapman SB, Levin HS. Impairments in learning, memory, and metamemory following childhood head injury. J Head Trauma Rehabil. 2011 June;26:192-201.

35. Josman N, Berney T, Jarus T. Evaluating Categorization Skills in Children Following Severe Brain Injury. Occupational Therapy Journal of Research. 2000 January [cited 2014 November 10];20:241-55.

36. Cicerone KD, Langenbahn DM, Braden C, Malec JF, Kalmar K, Fraas M, Felicetti T, Laatsch L, Harley JP, Bergquist T, et al. Evidence-Based Cognitive Rehabilitation: Updated Review of the Literature From 2003 Through 2008. Archives of Physical Medicine and Rehabilitation. 2011 April [cited 2012 July 27];92:519-530.

37. Krasny-Pacini A, Chevignard M, Evans J. Goal Management Training for rehabilitation of executive functions: a systematic review of effectivness in patients with acquired brain injury. 2013 April 18 [cited 2013 April 18]. Available from: http://informahealthcare.com/eprint/ijeZAnewNg5hUQWaYuny/full

38. Krasny-Pacini A, Limond J, Evans J, Hiebel J, Bendjelida K, Chevignard M. Context-Sensitive Goal Management Training for Everyday Executive Dysfunction in Children After Severe Traumatic Brain Injury. J Head Trauma Rehabil. 2014 February 3.

39. Bertens D, Fasotti L, Boelen DHE, Kessels RPC. A randomized controlled trial on errorless learning in goal management training: study rationale and protocol. BMC Neurol. 2013;13:64.

31 Awareness pilot study, November 2014

URL: http:/mc.manuscriptcentral.com/dandr Email: davemuller@suffolk.ac.uk 
40. Levine B, Schweizer TA, O'Connor C, Turner G, Gillingham S, Stuss DT, Manly T, Robertson IH. Rehabilitation of Executive Functioning in Patients with Frontal Lobe Brain Damage with Goal Management Training. Front Hum Neurosci [Internet]. 2011 February 17 [cited 2012 July 27];5. Available from: http://www.ncbi.nlm.nih.gov/pmc/articles/PMC3043269/

41. Robertson IH, Levine B, Manly T. Goal Management Training: PowerPoint support slides.

42. Spikman JM, Boelen DHE, Lamberts KF, Brouwer WH, Fasotti L. Effects of a multifaceted treatment program for executive dysfunction after acquired brain injury on indications of executive functioning in daily life. J Int Neuropsychol Soc. 2010 January [cited 2012 July 27];16:118-129.

43. Miotto EC, Evans JJ, Souza de Lucia MC. Rehabilitation of executive dysfunction: A controlled trial of an attention and problem solving treatment group. Neuropsychological Rehabilitation. 2009 [cited 2012 July 27];19:517-540.

44. Lyons KE, Zelazo PD. Monitoring, metacognition, and executive function: elucidating the role of selfreflection in the development of self-regulation. Adv Child Dev Behav. 2011 [cited 2012 August 22];40:379-412.

45. Dermitzaki I. PRELIMINARY INVESTIGATION OF RELATIONS BETWEEN YOUNG STUDENTS' SELFREGULATORY STRATEGIES AND THEIR METACOGNITIVE EXPERIENCES 1,2. Psychological Reports. 2005 December [cited 2012 August 21];97:759-768.

46. Chevignard MP, Servant V, Mariller A, Abada G, Pradat-DiehI P, Laurent-Vannier A. Assessment of executive functioning in children after TBI with a naturalistic open-ended task: A pilot study. Developmental Neurorehabilitation. 2009 January [cited 2012 July 27];12:76-91.

47. Chevignard MP, Catroppa C, Galvin J, Anderson V. Development and Evaluation of an Ecological Task to Assess Executive Functioning Post Childhood TBI: The Children's Cooking Task. Brain Impairment. 2010;11:125-143.

48. Ownsworth T, Clare L. The association between awareness deficits and rehabilitation outcome following acquired brain injury. Clinical Psychology Review. 2006 October [cited 2012 August 23];26:783-795.

49. Hart T, Whyte J, Kim J, Vaccaro M. Executive function and self-awareness of "real-world" behavior and attention deficits following traumatic brain injury. J Head Trauma Rehabil. 2005 August [cited 2012 July 27$] ; 20: 333-347$.

50. Prigatano GP, Altman IM, O'brien KP. Behavioral limitations that traumatic-brain-injured patients tend to underestimate. Clinical Neuropsychologist. 1990 [cited 2013 December 11];4:163-176.

51. Leathem JM, Murphy LJ, Flett RA. Self- and Informant-Ratings on the Patient Competency Rating Scale in Patients with Traumatic Brain Injury. Journal of Clinical and Experimental Neuropsychology. 1998 [cited 2013 December 11];20:694-705.

52. Sherer M, Bergloff P, Boake C, High Jr W, Levin E. The Awareness Questionnaire: factor structure and internal consistency. Brain Injury. 1998 January [cited 2013 December 11];12:63-68.

53. Dennis M, Simic N, Gerry Taylor H, Bigler ED, Rubin K, Vannatta K, Gerhardt CA, Stancin T, Roncadin C, Yeates KO. Theory of mind in children with traumatic brain injury. J Int Neuropsychol Soc. 2012 September;18:908-916.

32 Awareness pilot study, November 2014

URL: http:/mc.manuscriptcentral.com/dandr Email: davemuller@suffolk.ac.uk 
54. Dennis M, Agostino A, Taylor HG, Bigler ED, Rubin K, Vannatta K, Gerhardt CA, Stancin T, Yeates KO. Emotional expression and socially modulated emotive communication in children with traumatic brain injury. J Int Neuropsychol Soc. 2013 January;19:34-43.

55. Bach $\sqcup$, David AS. Self-awareness after acquired and traumatic brain injury. Neuropsychol Rehabil. 2006 August [cited 2012 July 27];16:397-414.

56. Koriat A, Ackerman R. Metacognition and mindreading: judgments of learning for Self and Other during self-paced study. Conscious Cogn. 2010 March;19:251-264.

57. Williams D. Theory of own mind in autism Evidence of a specific deficit in self-awareness? Autism. 2010 January 9 [cited 2013 November 26];14:474-494.

58. Stuss DT, Anderson V. The frontal lobes and theory of mind: Developmental concepts from adult focal lesion research. Brain and Cognition. 2004 June [cited 2014 November 10];55:69-83.

59. Rosenzweig C, Krawec J, Montague M. Metacognitive strategy use of eighth-grade students with and without learning disabilities during mathematical problem solving: a think-aloud analysis. J Learn Disabil. 2011 December [cited 2012 August 21];44:508-520.

60. Hart T, Giovannetti T, Montgomery MW, Schwartz MF. Awareness of errors in naturalistic action after traumatic brain injury. The Journal of Head Trauma Rehabilitation. 1998;13:16-28.

61. Larson MJ, Fair JE, Farrer TJ, Perlstein WM. Predictors of performance monitoring abilities following traumatic brain injury: the influence of negative affect and cognitive sequelae. Int J Psychophysiol. 2011 October;82:61-68.

62. Larson MJ, Perlstein WM. Awareness of deficits and error processing after traumatic brain injury. Neuroreport. 2009 October 28;20:1486-1490.

63. Bettcher BM, Giovannetti T, Macmullen L, Libon DJ. Error detection and correction patterns in dementia: a breakdown of error monitoring processes and their neuropsychological correlates. J Int Neuropsychol Soc. 2008 March;14:199-208.

64. Yochim BP, Baldo JV, Kane KD, Delis DC. D-KEFS Tower Test performance in patients with lateral prefrontal cortex lesions: the importance of error monitoring. J Clin Exp Neuropsychol. 2009 August;31:658-663.

65. Ownsworth T, Fleming J, Tate R, Shum DH, Griffin J, Schmidt J, Lane-Brown A, Kendall M, Chevignard $M$. Comparison of error-based and errorless learning for people with severe traumatic brain injury: study protocol for a randomized control trial. Trials. 2013 [cited 2014 April 29];14:369.

66. Piolino P, Hisland M, Ruffeveille I, Matuszewski V, Jambaqué I, Eustache F. Do school-age children remember or know the personal past? Conscious Cogn. 2007 March;16:84-101.

67. Nelson K, Fivush R. The Emergence of Autobiographical Memory: A Social Cultural Developmental Theory. Psychological Review. 2004;111:486-511.

68. Perner J, Dienes Z. Developmental aspects of consciousness: how much theory of mind do you need to be consciously aware? Conscious Cogn. 2003 March;12:63-82.

69. Dirette D. The development of awareness and the use of compensatory strategies for cognitive deficits. Brain Injury. 2002 January [cited 2012 August 23];16:861-871. 
70. Bjorklund DF. Children's Thinking: Cognitive Development and Individual Differences. Cengage Learning; 2011.

71. Piolino P, Desgranges B, Manning L, North P, Jokic C, Eustache F. Autobiographical memory, the sense of recollection and executive functions after severe traumatic brain injury. Cortex. 2007 February;43:176-195. 
Figure 1: Correspondence between Crosson's and Toglia and Kirk's model and Developmental psychology terminology $254 \times 190 \mathrm{~mm}(96 \times 96 \mathrm{DPI})$

URL: http:/mc.manuscriptcentral.com/dandr Email: davemuller@suffolk.ac.uk 


\begin{tabular}{l}
4 \\
5 \\
\cline { 3 - 3 }
\end{tabular}

\begin{tabular}{|c|c|c|c|c|c|}
\hline 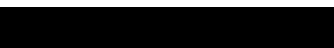 & $\mathbf{Y R}$ & PB & CS & $\mathbf{R K}$ & $\mathbf{I P}$ \\
\hline Sex & Boy & Girl & Girl & Boy & Boy \\
\hline Age at inclusion (years) & 14 & 11 & 11 & 13 & 8 \\
\hline & \multicolumn{5}{|c|}{ Medical history } \\
\hline Age at injury (years) & 2.5 & 2.5 & 6.5 & 7 & 5.5 \\
\hline nitial GCS & $<7$ & 6 & 4 & 3 & 6 \\
\hline Brain imaging & Unknown & $\begin{array}{l}\text { Large right hemisphere } \\
\text { hemorrhage and edema, } \\
\text { right parietal depression }\end{array}$ & $\begin{array}{l}\text { Cerebellar and right parieto- } \\
\text { occipital lesion with } \\
\text { depression fracture }\end{array}$ & $\begin{array}{l}\text { Subdural hematoma with } \\
\text { diffuse edema and } \\
\text { pneumocephalus }\end{array}$ & $\begin{array}{l}\text { Brain stem hemorrhage, } \\
\text { Diffuse subarachnoid } \\
\text { hemorrhage }\end{array}$ \\
\hline
\end{tabular}

fracture

$\begin{array}{lllll}\text { uration of coma (days) } & \text { Unknown } & \text { Unknown } & 1 & 10\end{array}$

ssociated impairments, Severe behavioral $\quad$ Epilepsy absences treated by

disorders carbamazepine language pragmatics left arm weakness

\begin{tabular}{|llll}
\hline Glasgow Outcome Scale & 3 (severe) & 2 (moderate) & 3 (severe) \\
\hline
\end{tabular}

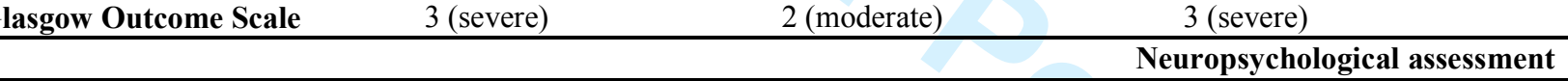

$\begin{array}{lllccc}\text { WISC IV matrices } & 11 & 9 & 7 & 11\end{array}$

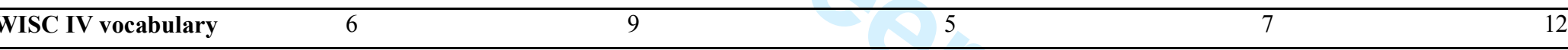

$\begin{array}{llllll}\text { BADS-C } 6 \text { part test } & 7 & 10 & 7 & 8\end{array}$

\begin{tabular}{|c|c|c|c|c|c|}
\hline CMS stories - immediate & 9 & 8 & 8 & 4 & 8 \\
\hline CMS stories- delayed & 8 & 5 & 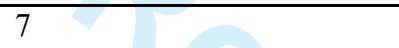 & 4 & 9 \\
\hline CMS backward span & Missing data & 8 & 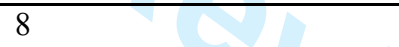 & 10 & 18 \\
\hline CMS words list - immediate & Missing data & 9 & 7 & 12 & 14 \\
\hline CMS words list - delayed & Missing data & 13 & 2 & 16 & 16 \\
\hline Parents BRIEF T-score: BRI & 63 & 71 & 87 & 95 & 57 \\
\hline Parents BRIEF T-score: MI & 68 & 82 & 76 & $\bar{P}$ & 56 \\
\hline Parents BRIEF T-score: GEC & 68 & 80 & 82 & 88 & 57 \\
\hline Parents DEX-C : Z score & 3,53 & 4,7 & 3,7 & 5,1 & 0,7 \\
\hline \multirow[t]{3}{*}{ CCT: Z-score } & $\begin{array}{l}\text { Scoring impossible } \\
\text { due to complete } \\
\text { failure on task }\end{array}$ & 4,8 & 2,2 & 7,1 & 18,0 \\
\hline & \multicolumn{5}{|c|}{ Effect of Intervention (Context-sensitive pediatric Goal Management Training) } \\
\hline & Dropped out & $\begin{array}{l}\text { Improved on EF } \\
\text { questionnaires. No effect on } \\
\text { cooking task. }\end{array}$ & $\begin{array}{l}\text { Improved on EF } \\
\text { questionnaires. No effect on } \\
\text { cooking task. }\end{array}$ & $\begin{array}{l}\text { Improved on EF } \\
\text { questionnaires and } \\
\text { cooking task. }\end{array}$ & $\begin{array}{l}\text { Adequate application of } \\
\text { strategies on complex tasks, } \\
\text { improved on cooking task, no } \\
\text { effect on EF questionnaires }\end{array}$ \\
\hline
\end{tabular}

Table 1: Demographic, medical and neuropsychological characteristics of the participants

URL: http:/mc.manuscriptcentral.com/dandr Email: davemuller@suffolk.ac.uk 
Note: GCS: Glasgow Coma Scale score; ToM: Theory of Mind; FSIQ: Full Scale Intellectual Quotient; ADHD: Attention Deficit-Hyperactivity Disorder; WISC [1]: Wechsler Intelligence Scale for Children; BADS-C: Behavioural Assessment of the Dysexecutive Syndrome for Children; CMS [2]: Children's Memory Scale; BRIEF [3]' [4]: Behavior Rating Inventory of Executive Functions; BRI: Behavioral Regulation Index; MI: Metacognition Index; GEC: Global Executive Composite Score. DEX-C [5]: Dysexecutive questionnaire for children. CCT [6]'[7]: Children's Cooking Task. Neuropsychological test results are reported as standard scores, unless otherwise stated. For the CCT and for executive functions questionnaires, BRIEF and DEX-C, a higher score indicates greater impairment. The clinical cut-off score for the BRIEF is set at a Tscore of 65. Paper and pencil tests of executive functions (EF) [8] and detailed effect of intervention are reported elsewhere; all children had at least two out of three EF tests indicating impairment relative to controls $(<2 S D$ below controls' scores) $[9]$.

\section{References of tests used:}

Wechsler D. WISC-IV: échelle d'intelligence de Wechsler pour enfants : manuel d'interprétation. ECPA - Les Ed. du Centre de psychologie appliquée; 2005.

Cohen M. Echelle de Mémoire pour Enfants. Les éditions du centre de psychologie appliquée.; 2001.

Gioia GA, Isquith PK, Guy SC, Kenworthy L. Behavior Rating Inventory of Executive Function® (BRIEF®). 2000.

Gioia GA, Isquith PK, Guy SC, Kenworthy L. Behavior Rating Inventory of Executive Function ${ }^{\circledR}$ (BRIEF®). Adaptation française A. Roy, N. Fournet, D. Legall, J-L Roulin. Hogrefe; 2000.

Emslie H. Behavioural Assessment of the Dysexecutive Syndrome for Children: (BADS-C). Thames Valley Test Company; 2003.

Chevignard MP, Catroppa C, Galvin J, Anderson V. Development and Evaluation of an Ecological Task to Assess Executive Functioning Post Childhood TBI: The Children's Cooking Task. Brain Impair. 2010;11:125-143.

Chevignard MP, Servant V, Mariller A, Abada G, Pradat-Diehl P, Laurent-Vannier A. Assessment of executive functioning in children after TBI with a naturalistic openended task: A pilot study. Dev Neurorehabilitation. 2009 January [cited 2012 July 27];12:76-91.

Roy A, Roulin J-L, Le Gall D, Fournier N, Groupe FEE. Fonctions Exécutives chez l'Enfant. unpublished

Krasny-Pacini A, Limond J, Evans J, Hiebel J, Bendjelida K, Chevignard M. Context-Sensitive Goal Management Training for Everyday Executive Dysfunction in Children After Severe Traumatic Brain Injury. J Head Trauma Rehabil. 2014 February 3. 


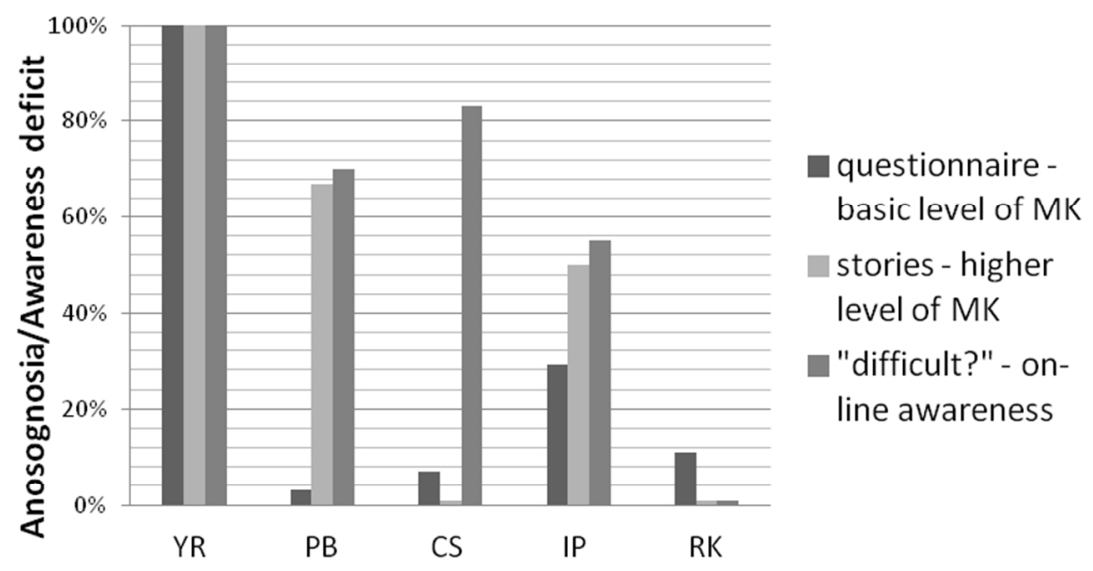

Figure 2: Anosognosia/Awareness deficit scores for each type of awareness. Note: Higher scores indicate that children are more anosognosic/unaware, i.e. representing a deficit in awareness. Lower scores reflect better awareness. MK: metacognitive knowledge; VR, PB, CS, IP, RK: children's initials.

Anosognosia/Awareness deficit scores for each type of awareness $254 \times 190 \mathrm{~mm}(96 \times 96 \mathrm{DPI})$ 


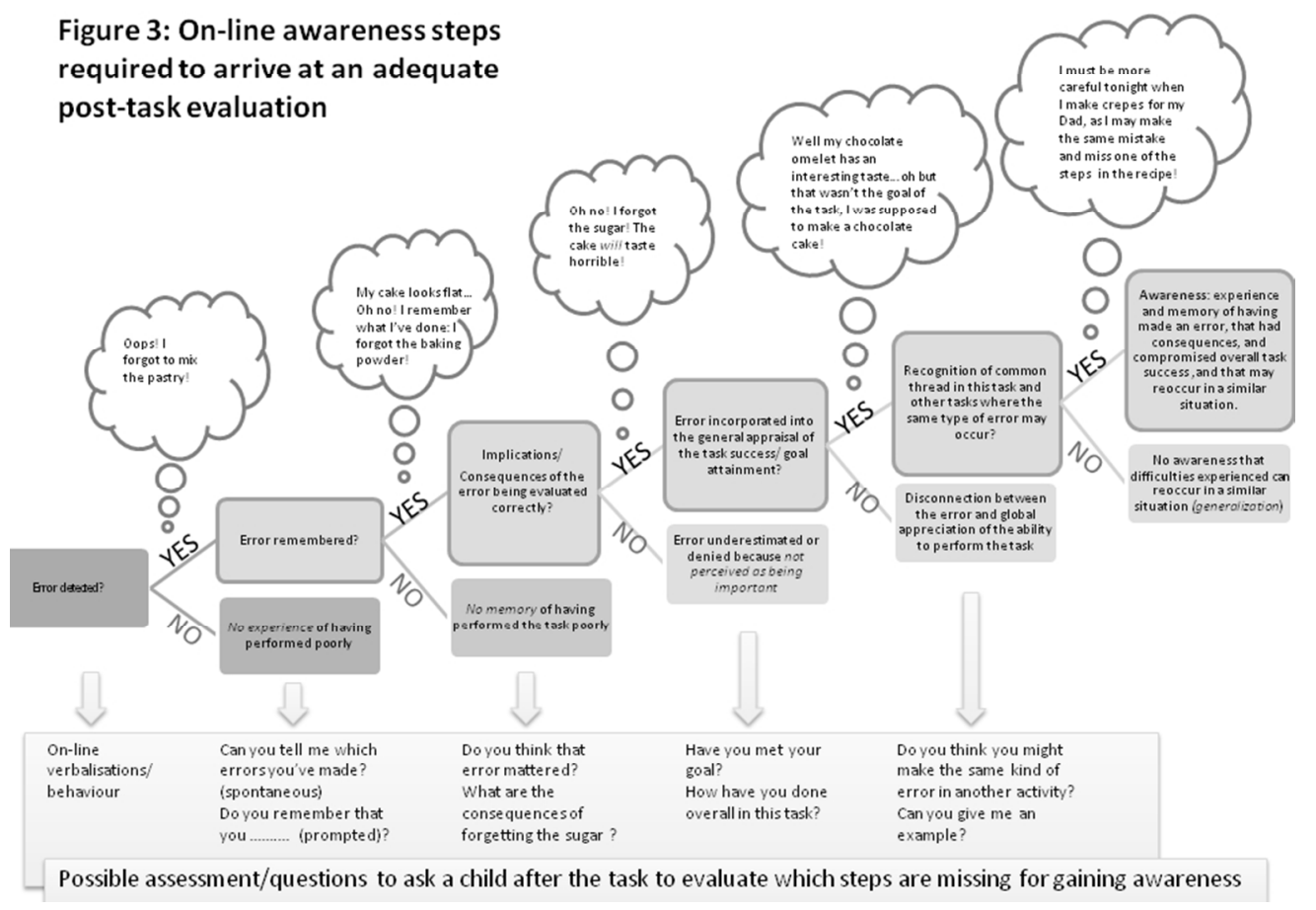

Figure 3: On-line awareness steps required to arrive at an adequate post-task evaluation $254 \times 190 \mathrm{~mm}(96 \times 96 \mathrm{DPI})$ 
Figure 4: Autobiographical awareness mediated by on-line experience model. We hypothesise that the relative importance of different inputs varies with developmental age.

$$
254 \times 190 \mathrm{~mm}(96 \times 96 \text { DPI) }
$$


Anticipatory awareness

Figure 5: Proposed framework for awareness assessment $254 \times 190 \mathrm{~mm}(96 \times 96 \mathrm{DPI})$ 


\section{Appendix 1: Adapted Goal Management Training questionnaire for children}

Does it happen to you...

- Walking into a room and forgetting what it was that you had come for?

- Finding that you don't have time to stop and think?

- Forgetting something that needed to be done at a certain time (e.g. calling someone, taking your medication, go to your sports lesson, a TV programme that you wanted to watch)?

- Making a mistake because you weren't thinking about what you were doing at the time?

- Not remembering where you had got to in a task/ an exercise at school?

- Spending too long searching for things (e.g. school bag, keys, shoes) because you don't remember where you put them?

- Finding that you have done things in the wrong order?

- Feeling that others expect too much from you?

- Losing track of time?

- Running out of time because you got too caught up in something that you were doing (e.g. spending time tidying your desk at school and not finishing a test on time)?

- Having difficulty making decisions?

- Daydreaming rather than thinking about what you were doing?

- Having problems organizing your time (e.g. arranging in which order to do your homework, not finishing a test on time, not giving yourself enough time to get somewhere, being late)?

- Keeping making the same mistakes (e.g. when using a computer, doing a math exercise at school or building a construction)?

- Having to go back to get something that you had forgotten to take with you?

- Not thinking something through before acting?

- Starting an exercise and realising once you've started that are not doing what was asked?

- Avoiding thinking about a problem because it just seems too complicated?

- Do sometimes feel that you don't know where to begin in order to carry out a task (a school assignment, a construction, homework...)?

- Does it happen that you read the instructions at school too quickly and fail the exercise because of that?

- Do you manage to estimate how long a task will take you before starting it? (e.g.: tidying your room, going to a friend's house to fetch school work, solving a math exercise)

- Do you manage to estimate how difficult an exercise is before starting it?

- Do you sometimes feel that things go too quickly for you and that you don't manage to keep up?

- Do you sometimes find that you haven't been listening to important information that your teacher or parents were telling you?

- Is it difficult for you to think about, or to do two things at the same time?

- Do you manage to prepare your school bag alone without forgetting anything?

- Do you sometimes forget if you have done something (ex: feeding your pet, closing the entrance door, finishing your homework)?

- Do you sometimes forget important things you had to do and do something else instead? (e.g: go on the computer for 10 minutes and find out one hour later that you forgot to do your homework)

- Do you sometimes feel there are too many things, too much information in your head and that you don't manage to deal with them?

- Do you sometimes find that your brain wanders away from what you are doing?

- Do you sometimes feel that you know how to carry out an exercise or a task, but once you're doing it, things get mixed up in your head?

This is a translation of the French questionnaire used in the study $y^{38}$. All items relate to the content of the intervention (Context-sensitive Goal Management Training), that focused on improving executive functions and prospective memory. The questionnaire has not been validated and needs further adaptations if used outside the context of the intervention. 


\section{Figure 3: On-line awareness steps required to arrive at an adequate post-task evaluation}

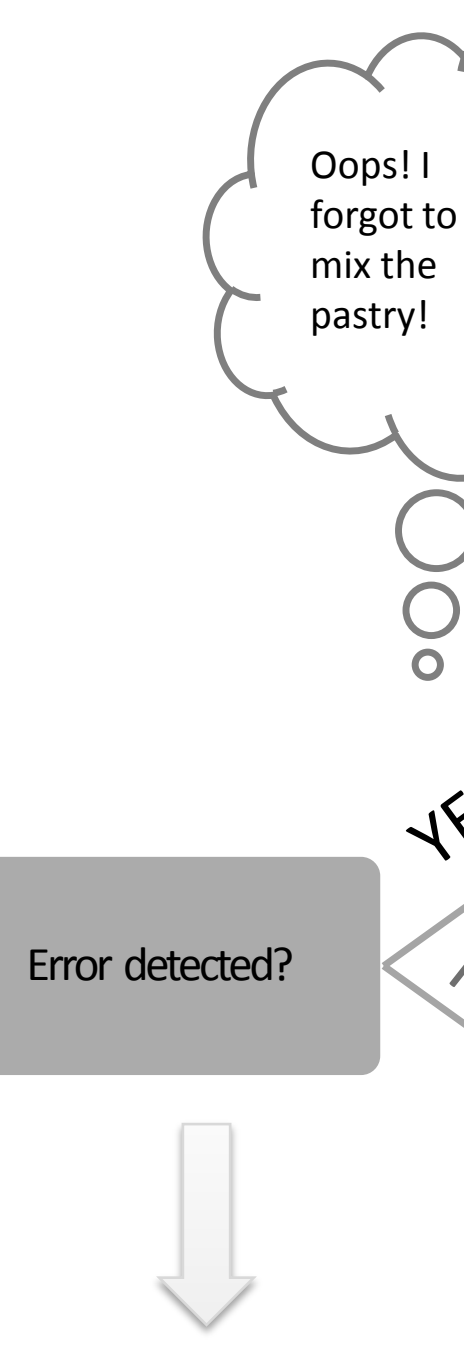

\section{On-line} verbalisations/ behaviour
Can you tell me which errors you've made? (spontaneous) Do you remember that you .......... (prompted)?
No experience of having performed poorly
My cake looks flat... Oh no! I remember what l've done: I forgot the baking powder!

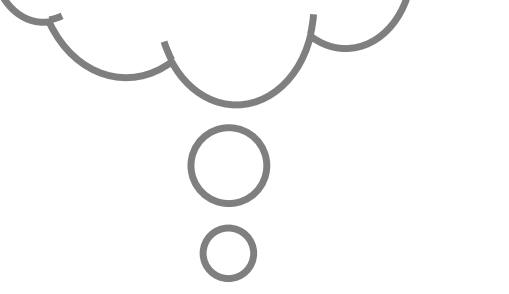

Implications/ Consequences of the error being evaluated correctly?

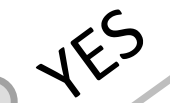

Error remembered? ?

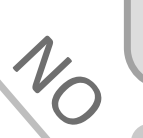

No memory of having performed the task poorly

\section{Oh no! I forgot} the sugar! The cake will taste horrible!

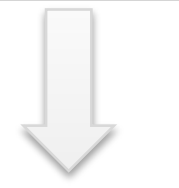

Do you think that error mattered? What are the consequences of forgetting the sugar?
I must be more

careful tonight when I make crepes for my

Dad, as I may make

the same mistake and

miss one of the steps

omelet has an

interesting taste... oh

but that wasn't the

goal of the task, I was

supposed to make a

chocolate cake!
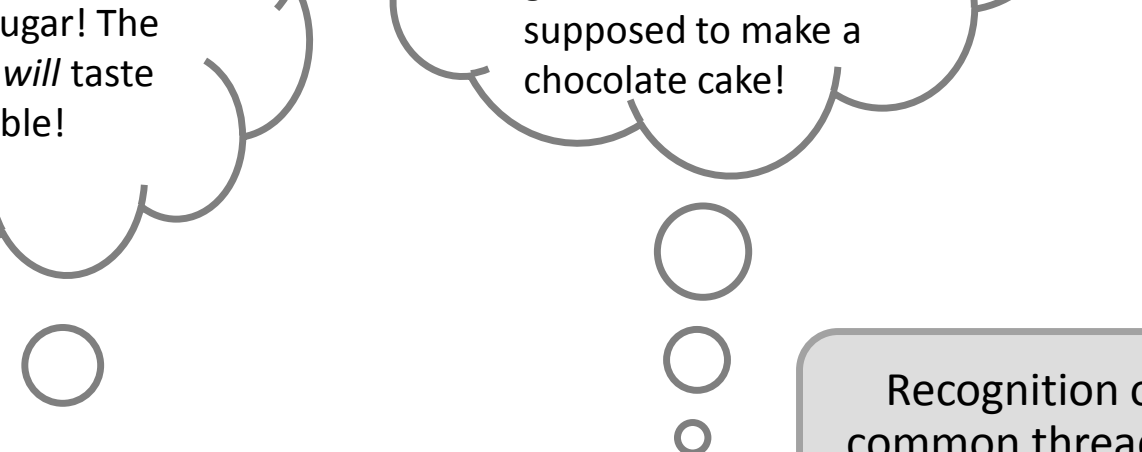

rror incorporated into the general appraisal of the task success/goal attainment?

Error underestimated or denied because not perceived as being important

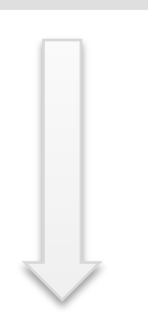

Have you met your goal?

How have you done overall in this task? ability to perform the task

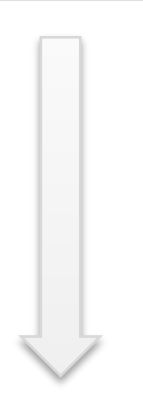

Do you think you might make the same kind of error in another activity? Can you give me an
Awareness: experience and memory of having made an error, that had consequences, and compromised overall task success, and that may reoccur in a similar situation.

No awareness that difficulties experienced can reoccur in a similar situation (generalization)

example? 